Borneo Journal of Science \& Technology, Volume (2), Issue (2), Pages: 77-80

DOI: http://doi.org/10.3570/bjost.2020.2.2-12

e-ISSN: 2672-7439

(C) 2018, UCTS Publisher.

Submitted: $22^{\text {th }}$ May 2019

Accepted: $13^{\text {th }}$ January 2020

Published: $31^{\text {th }}$ July 2020

\title{
Sensory Evaluation on the Concentrated Pineapple Juice Produced through Reverse Osmosis Process
}

\author{
Mohammad Hafsanjani Salleh, *Zahid Abidin and Ashraf A. Razak \\ School of Engineering and Technology, University College of Technology Sarawak (UCTS), \\ 96000 Sibu, Sarawak
}

\begin{abstract}
The objective of this study is to evaluate the sensory properties of the concentrated pineapple juice produced through reverse osmosis process. Fresh pineapple juices were treated at four different combinations of pressure (20 to $60 \mathrm{bar}$ ) and temperature $\left(20\right.$ to $60^{\circ} \mathrm{C}$ ), and the concentrated juices produced were evaluated for the sensory properties in terms of colour, aroma, sweetness, sharpness/sourness, overall acceptability and purchase intention. The juice with highest score in the overall acceptability was then further compared with a selected commercial pineapple juice. Among all the treatments, pineapple juice produced at 60 bar and $20^{\circ} \mathrm{C}$ was determined to be the most preferred by the majority of the panellists. Also, the comparison between treated pineapple juice and the commercial indicate that the majority of the panellist significantly preferred the pineapple juice produced through reverse osmosis especially in term of purchase intention.
\end{abstract}

Keywords: Reverse Osmosis, Pineapple, Fruit Juice, Concentration, Sensory Evaluation.

\section{INTRODUCTION}

Malaysia is one of the country that planted pineapples as one of the major crops besides papaya, pomelo, banana, watermelon, jackfruit and mango. According to a database reported by the Malaysian Pineapple Industry Board (MPIB), Malaysia was ranked at 18 as major world producer in 2010 and increased to rank 15 in 2014 [1]. Pineapple is popular for it unique taste in term of sourness and sweetness which is balanced. Furthermore, pineapple is nutritious, beneficial to health while having important values in the aspect of medicines. Pineapple is usually processed into various product including canned pineapple, fresh juice, candies and also concentrated juice [2].

Concentrated juice is a convenient product as it is easy to be packaged, have longer shelf-life, low microbial activity and highly stable [3]. Concentrated juice is conventionally produced through thermal evaporation which involves heat transfer principle to remove the water molecules. Thermal evaporation is an effective technique in obtaining high total soluble solids of up to $60^{\circ} \mathrm{Brix}$, which meet the standard and definition for the concentrated juice [4]. However, one of the major drawback of the thermal evaporation technique is the quality deterioration in the juices due to the degradation of the heat intolerance compounds such as vitamins and minerals [5]. To preserve the quality of the concentrated juice, a non-thermal technique such as reverse osmosis may be considered as a new approach.

Reverse osmosis is a process that separate the water molecules from the solution based on the concentration gradient through a semi-permeable membrane by applying pressure [7]. In comparison with the thermal evaporation, reverse osmosis is more environmental friendly, less energy consumption and it can be operated at the low temperature [6]. Also, thermal degradation of the sensitive compounds such as vitamins and minerals could be avoided as well as enhancing the other juice properties such as antioxidant capacity, colour and texture of the fruit juice [8].

The study on the physicochemical properties alone is insufficient in determining the quality of the juice produced from the reverse osmosis process. The juice may also be viewed in the sense of organoleptic properties through the sensory tests which more appropriate in determining the quality of the fruit juice as illustrated in Figure 1 [9]. Critical intrinsic and extrinsic characteristics of the final product may also help in rough qualitative visualisation and the marketability status [10].

The objective of this study is to evaluate the sensory properties of the concentrated pineapple juices produced at four different treatments by reverse

Corresponding Author: Zahid Abidin, School of Engineering and Technology, University College of Technology Sarawak

(UCTS), E-mail: zahidabidin@ucts.edu.my 
osmosis process. Also, a comparison study were made between the best pineapple juice and the selected commercial pineapple juice.

The first stage of sensory test is to evaluate the pineapple juices treated at four different concentrations treatment. The treated pineapple juice with the highest overall acceptability score was chosen for the second stage of sensory test.

In the second stage, the treated pineapple juice will be compared with a selected commercial pineapple juice. The criteria for the evaluations were set similar to the first stage except that an additional of one more criteria namely purchase intention.

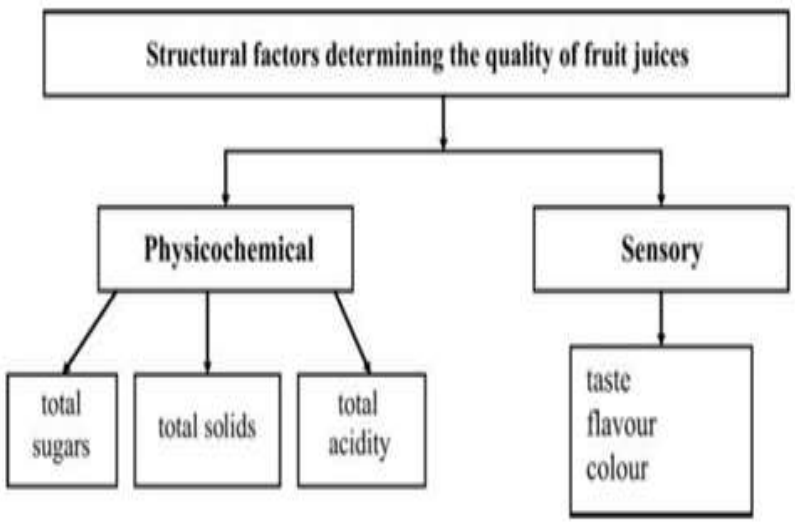

Figure 1. Structural model of factors determining the quality of fruit juices. Kraus and Popek [9]

\section{MATERIALS AND METHODS}

\section{Concentration process}

Two-level full factorial design was used for the experimental design and each run was done in triplicate. The pineapple juices were concentrated at four different treatments according to the factorial design as follow:
i) $\mathrm{A}\left(20\right.$ bar and $\left.20^{\circ} \mathrm{C}\right)$
ii) $\mathrm{B}\left(20\right.$ bar and $\left.60^{\circ} \mathrm{C}\right)$
iii) $\mathrm{C}\left(60\right.$ bar and $\left.20^{\circ} \mathrm{C}\right)$
iv) $\mathrm{D}\left(60\right.$ bar and $\left.60^{\circ} \mathrm{C}\right)$.

The reverse osmosis system used is a single-stage configuration with an output rate of 150 gallon per day of treated water. Also, a membrane with the spiral type (DOW Filmtech SW30-2514), stabilised salt rejection of $99.4 \%$ and $0.7 \mathrm{~m}^{2}$ effective surface area was selected as part of the reverse osmosis system.

Prior concentration process at $40{ }^{\circ} \mathrm{C}$ and $60{ }^{\circ} \mathrm{C}$, pineapple juices was pre-heated using water bath technique (Memmert waterbath WNB45). The cover of waterbath system was left open during heating to avoid potential droplets formation from entering the pineapple juice. Also, opening the cover ease the process of monitoring of the pineapple juice temperature using thermometer.

\section{Sensory test}

Sensory attributes such as colour, aroma, sweetness, tartness or sharpness and overall acceptability were evaluated using five-point hedonic scales and ten semitrained panellist [11]. The panellist are selected randomly with no specific allergic to any tropical fruits. The tests were carried out in the food sensory laboratory with well-prepared instrumentation and design facility. Two stages of sensory test were conducted and the results obtained were compared using t-test to check for any significant difference.

\section{RESULTS AND DISCUSSION}

Table 1 shows the results of the sensory evaluation of the treated pineapple juice. In term of colour criteria, the majority panellists favoured the treated pineapple juice C. This could be due to the intense colour produced at low temperature and high transmembrane pressure condition [12]. In contrast, pineapple juice produced at high temperature and low transmembrane pressure has the least colour score which represented by the treatment B. High temperature had a negative impact on the colour of the juice as it may cause the discolouration effect during the concentration process. Also, high temperature may cause degradation of heat sensitive component in the juice and subsequently can promote the caramelization, Maillard reaction or nonenzymatic browning process [13]. The brown pigment formation due to the effect of high temperature treatment may darken the juice and thus reducing the score for the colour appearance.

Pleasant aroma is one of the classical trait of tropical fruits due the aromatic properties which exhibit unique fragrant and varies according to the cultivars, agro-cultural practices and seasonal changes [14]. Juice from the treatment $\mathrm{C}$ scores the highest values probably because of the critical retention of aromatic compounds through low temperature and high during the concentration process. On the other hand, the juice from treatment B produced lowest score in terms of aroma characteristic. This could be due to the effect of high temperature applied during the concentration process. The high temperature during concentration process promote the permeability of the aromatic compounds through the membrane of reverse osmosis which allow the escape of the volatile compounds together with the permeate materials. Thus, the final juice produced at the high temperature treatment show less aroma intensity. 


\section{Sensory Evaluation on the Concentrated Pineapple Juice Produced through Reverse Osmosis Process}

For sweetness of the pineapple juices, majority of the panellist favoured treated pineapple juice $\mathrm{C}$ and $\mathrm{D}$. The scores obtained for treatments $\mathrm{C}$ and $\mathrm{D}$ are significantly different with the treatments $\mathrm{A}$ and $\mathrm{B}$. The difference of this scores could be due to the total soluble solids contents that represents the degree of the natural sweetness which were relatively high in the treatments $\mathrm{C}$ and $\mathrm{D}$. As for $\mathrm{A}$ and $\mathrm{B}$, both juices were treated at low transmembrane pressure where the concentration process by reverse osmosis process is less effective. Thus, the concentration process at low transmembrane pressure yields low percentage of total soluble solids.

Table 1: Results of sensory evaluation for different treatments of pineapple juices

\begin{tabular}{|c|c|c|c|c|}
\hline \multirow{2}{*}{$\begin{array}{l}\text { Pineapple } \\
\text { juice } \\
\text { characteristics }\end{array}$} & \multicolumn{4}{|c|}{ Average score } \\
\hline & $\mathrm{A}$ & $\mathrm{B}$ & $\mathrm{C}$ & $\mathrm{D}$ \\
\hline Colour & $3.7 \pm 0.23^{\mathrm{a}}$ & $3.2 \pm 0.12^{\mathrm{b}}$ & $4.0 \pm 0.26^{\mathrm{a}}$ & $\begin{array}{l}3.3 \pm 0.28^{a} \\
b\end{array}$ \\
\hline Aroma & $2.2 \pm 0.34^{\mathrm{a}}$ & $2.1 \pm 0.23^{\mathrm{a}}$ & $2.6 \pm 0.26^{\mathrm{a}}$ & $2.4 \pm 0.19^{\mathrm{a}}$ \\
\hline Sweetness & $2.0 \pm 0.30^{\mathrm{a}}$ & $2.2 \pm 0.23^{\mathrm{a}}$ & $3.3 \pm 0.18^{b}$ & $3.4 \pm 0.10^{\mathrm{b}}$ \\
\hline $\begin{array}{l}\text { Tartness/ } \\
\text { sharpness }\end{array}$ & $2.9 \pm 0.31^{\mathrm{a}}$ & $3.1 \pm 0.32^{\mathrm{a}}$ & $3.8 \pm 0.24^{b}$ & $3.5 \pm 0.25^{\mathrm{b}}$ \\
\hline $\begin{array}{l}\text { Overall } \\
\text { acceptability }\end{array}$ & $2.6 \pm 0.24^{\mathrm{a}}$ & $2.8 \pm 0.35^{\mathrm{a}}$ & $3.8 \pm 0.25^{\mathrm{b}}$ & $3.2 \pm 0.23^{b}$ \\
\hline
\end{tabular}

One of the crucial attributes of the tropical based fruit juices is the tartness or sharpness sensation due to the ascorbic acid and other organic acids contents. Based on the results (Table 1), panellists were preferred juice from treatment $\mathrm{C}$ which could be due to the high preservation of ascorbic acid during the concentration process. Ascorbic acid is considered as a thermal sensitive compound and could be degraded under extreme temperature beyond its stability threshold [15];[16]. Also, the factor of high transmembrane pressure applied had an advantageous effect on the preservation of ascorbic acid. Higher transmembrane pressure promote better retention of ascorbic acids than that of the lower pressure. Therefore, treatment $\mathrm{C}$ has the highest score among all treatments due to low thermal and high transmembrane pressure factors that maximise the retention of ascorbic acid and other organic acids [12].

A second stage of sensory test was conducted between the most preferred pineapple juice with the highest overall acceptability score (treatment $\mathrm{C}$ ) and a selected commercial pineapple juice. The criteria for evaluation were set similar to the first stage except that a new characteristic namely purchase intention was introduced. The purchase intention characteristic is used to measure the marketability of the pineapple juices produced by the reverse osmosis system. The result of both products were presented in Table 2 . The samples of pineapple juices were prepared according to the method employed by Deliza [17].

Table 2: Sensory evaluation results between the highest overall acceptability pineapple juice and selected commercial one

\begin{tabular}{lcc}
\hline \multirow{2}{*}{$\begin{array}{l}\text { Pineapple juice } \\
\text { characteristics }\end{array}$} & \multicolumn{2}{c}{ Average score } \\
\cline { 2 - 3 } Colour & $4.4 \pm 0.42^{\mathrm{a}}$ & $4.2 \pm 0.51^{\mathrm{a}}$ \\
Aroma & $2.7 \pm 0.53^{\mathrm{a}}$ & $2.4 \pm 0.60^{\mathrm{a}}$ \\
Sweetness & $3.2 \pm 0.35^{\mathrm{a}}$ & $3.3 \pm 0.37^{\mathrm{a}}$ \\
Tartness/sharpness & $3.1 \pm 0.62^{\mathrm{a}}$ & $3.0 \pm 0.55^{\mathrm{a}}$ \\
Overall & $3.5 \pm 0.38^{\mathrm{a}}$ & $3.2 \pm 0.42^{\mathrm{a}}$ \\
acceptability & & \\
Purchase intention & $4.5 \pm 0.44^{\mathrm{a}}$ & $3.6 \pm 0.30^{\mathrm{b}}$ \\
\hline Note: Identical letters in the same row do not differ \\
significantly (p>0.05) among themselves.
\end{tabular}

Table 2 demonstrated that the differences between both pineapple juices were insignificant in terms of colour, aroma, sweetness, tartness, and overall acceptability. However, the purchase intention of both pineapple juices were significantly different $(p<0.05)$ as verified through the t-test. The purchase intention was higher for the pineapple juice produced by the reverse osmosis than the commercial product. This could indicates that the high potential for marketability of the pineapple juice produced by the reverse osmosis system. This result is in agreement with the finding reported by Couto et al., [18] where the overall score for the pineapple juice produced by the reverse osmosis is higher than several selected local commercial pineapple juices. Also, panelist's preferences for the pineapple juice by the reverse osmosis over the commercial pineapple juices indicate that the quality preservation of the final product by the reverse osmosis is satisfactory [19].

\section{CONCLUSION}

Majority of the panelist preferred pineapple juice which was treated at $60 \mathrm{bar}$ transmembrane pressure and $20^{\circ} \mathrm{C}$ temperature. This was translated into the sensory scores where the juice produced through this treatment were superior in terms of colour, aroma, sweetness or sharpness and overall acceptability. When compared with a commercial pineapple juice, the sensory quality were comparable for both juices except for the purchase intention where majority panelist preferred the pineapple juice produced by the reverse osmosis. This study highlighted the potential of reverse osmosis technology as a promising technique to produce concentrated juice with an exceptional sensory quality. 


\section{ACKNOWLEDGMENT}

Thanks are due to University College Technology Sarawak for financial support and Malaysian Institute of Chemical and Bioengineering Technology (UniKLMICET), Melaka for project collaboration.

\section{REFERENCES}

[1] Amar, A., Tong, P. S. and Casey N. (2015). The MD2 'Super Sweet' pineapple (Ananas comosus). Agriculture Science Journal, 1(4), pp. 14-17.

[2] Dull, G.G. (1971). The pineapple general. In: Hulme, A.C. (ed.), The Biochemistry of Fruit and Their Products. Academic Press, New York 2(303), pp. 4-5.

[3] George B. J., Harold E. M., David W. S and Chien Y. M. (1999). Extending the shelf life of Fresh Cut Apples Using National Products and their Derivatives. Journal of Agricultural and Food Chemistry, 7(1), pp. 1-6.

[4] Ramteke, R. S., Eipeson, W. E., and Patwardhan, M. V. (1990). Behaviour of aroma volatiles during the evaporative concentration of some tropical fruit juices and pulps. Journal of the Science of Food and Agriculture, 50(3), pp. 399-405.

[5] Gimenez, R., Cabrera, C., Olalaa, M., Ruiz, M. D. and Lopez, M. C. (2002). Ascorbic acid in diet supplements: loss in the manufacturing process and storage. International Journal of Food Science and Nutrition, 33(6), pp. 509-518.

[6] Merson, R. L., Paredes, G., and Hosaka, D. B. (1980). Concentrating fruit juices by reverse osmosis. In Ultrafiltration membranes and applications. New York: Plenum Press, pp. 405.

[7] Cassano, A., Drioli, E., Galaverna, G., Marchelli, R., Di Silvestro, G. and Cagnasso, P. (2003). Clarification and concentration of citrus and carrot juices by integrated membrane processes. Journal of Food Engineering, 57, pp. 153-163.

[8] Jiao, B., Cassano, A. and Drioli, E. (2004). Recent advances on membrane processes for the concentration of fruit juices: a review. Journal of Food Engineering, 63, pp. 303-324.

[9] Kraus, A. and Popek, S. (2013). Structural model of fruit juice quality determining factors in product design and development. British Food Journal, 115(6), pp.865-875.

[10] Enneking, U., Neumann, C. and Henneberg, S. (2007). How important intrinsic and extrinsic product attributes affect purchase decision. Food Quality and Preference, 18(1), pp. 133-138.

[11]Larmond, E. (1997). Laboratory method for sensory evaluation of foods. Canada Dept. Agri. Pub., pp. 1637.

[12] Alvarez, V., Alvarez, S., Riera, F. A. and Alvarez, R. (1997). Permeate flux prediction in apple juice concentration by reverse osmosis. Journal of Membrane Science, 127, pp. 25-34.

[13] Barreiro, J. A., Milano, M. and Sandoval, A. J. (1997). Kinetics of colour change of double concentrated tomato paste during thermal treatment. Journal of Food Engineering, 33, pp. 359-371.

[14] Chuanhe, L., Yan, L., Ganjun, Y., Wenlong, L. and Guiping, Z. (2011). A comparison of aroma components of pineapple fruits ripened in different seasons. African Journal of Agricultural Research, 6(7), pp. 1771-1778.

[15]Leong, S. Y., and Oey, I. (2012). Effect of endogenous ascorbic acid oxidase activity and stability on vitamin $\mathrm{C}$ in carrots (Daucus carota subsp. sativus) during thermal treatment. Food Chemistry, 134(4), pp. 2075-2085.

[16] Phillips, K. M., Council-Troche, M., McGinty, R. C., Rasor, A. S., and Tarrago-Trani, M. T. (2016). Stability of vitamin $\mathrm{C}$ in fruit and vegetable homogenates stored at different temperatures. Journal of Food Composition and Analysis, 45, pp. 147-162.

[17] Deliza, R. (2001). The use of "ideal point" scale to determine the best sugar and dilution levels of passion fruit juice by consumers. Alimentaria, 38(24), pp. 109-113.

[18] Couto, D. S., Cabral, L. M. C., Virginia Martins, D. M., Deliza, R. and Freitas, D. G. C. (2011). Concentration of pineapple juice by reverse osmosis: physicochemical characteristic and consumer acceptance. Cienc-Tecnol. Aliment., Campinas, 31(4), pp. 905-910.

[19] Kozak, A., Banvolgyi, S., Vincze, I., Kiss, I., Bekassy-Molnar, E. and Vatai, G. (2008). Comparison of integrated large scale and laboratory scale membrane processes for the production of black currant juice concentrate. Chemical Engineering and Processing: Process Intensification, 47(7), pp. 1171-1177. 